UDC 338:330.131.7

LBC 65.28-09

\title{
RISK MANAGEMENT TO ENSURE ENVIRONMENTAL SAFETY AT ENTERPRISES
}

\author{
Anna A. Matveeva \\ Volgograd State University, Volgograd, Russian Federation
}

\begin{abstract}
The article raises the issue of environmental risk management for the formation of measures to ensure environmental safety in industrial enterprises. A classification of environmental risks is given depending on the nature and type of environmental impact. The paper describes the methods of environmental risk management. On the basis of which it is possible to build a further strategy of the enterprise to reduce or prevent the occurrence of risks depending on risk-forming factors of the environment. The concept of environmental risk management in an enterprise should be developed taking into account the economic conditions inherent in a particular enterprise, depending on the climatic and economic conditions of the region. Each industrial enterprise is unique in its field of activity, production volumes and a set of external and internal environmental factors. Therefore, environmental risk management can be classified as a targeted action aimed at choosing the optimal strategy for the enterprise to minimize environmental damage. The paper is proposed an algorithm for managing environmental risk for enterprises.

Key words: classification of the environmental risk, risk management, management methods of the environmental risk, strategy of the risk management, environmental safety, damage, region, industrial enterprise.
\end{abstract}

УДК 338:330.131.7

ББК 65.28-09

\section{УПРАВЛЕНИЕ РИСКАМИ ДЛЯ ОБЕСПЕЧЕНИЯ ЭКОЛОГИЧЕСКОЙ БЕЗОПАСНОСТИ НА ПРЕДПРИЯТИЯХ}

\author{
Анна Александровна Матвеева \\ Волгоградский государственный университет, г. Волгоград, Российская Федерация
}

\begin{abstract}
Аннотация. В статье поднимается вопрос об управлении экологическими рисками для формирования мероприятий по обеспечению экологической безопасности на промышленных предприятиях. Дана классификация экологических рисков в зависимости от характера и вида воздействия на окружающую среду. В работе указаны методы управления экологическими рисками, на основе которых можно построить дальнейшую стратегию предприятия по уменьшению или недопушению возникновения рисков в зависимости от рискообразующих факторов среды. Концепция управления экологическими рисками на предприятии должна быть разработана с учетом присущих конкретному предприятию условий хозяйствования в зависимости от физико-климатических и экономических условий региона. Каждое промышленное предприятие является уникальным по сфере своей деятельности, объемам производимой продукции и набору внешних и внутренних факторов среды. Поэтому управление экологическим риском можно классифицировать как целенаправленное действие, направленное на выбор оптимальной стратегии предприятия по минимизации экологического ущерба. В работе предложен алгоритм управления экологическим риском для предприятий.

Ключевые слова: классификация экологических рисков, управление рисками, методы управления экологическими рисками, стратегия управление рисками, экологическая безопасность, ущерб, регион, промышленное предприятие.
\end{abstract}

Актуальность исследований в данном явления конкретных механизмов управления рисками в пределах конкретных регионов. 


\section{ЭКОЛОГИЯ И ПРИРОДОПОЛЬЗОВАНИЕ}

Эксплуатация любых производственных объектов связана с возникающими рисками различного происхождения: финансово-экономическими, производственными и экологическими.

Под риском принято понимать возможность наступления некоторого неблагоприятного события, которое влечет за собой определенные потери [27-29].

Теория вероятности определяет риск, как количественный показатель опасности, вероятного ущерба, наступающего в результате проявления какого-либо неблагоприятного события. Он представляет собою многокомпонентную величину, измеренную, например, с помощью статистических данных или рассчитанную с помощью имитационных моделей, включающих количественные показатели. К таким количественным показателям относятся [1]:

- ущерб от воздействия того или иного опасного фактора;

- вероятность возникновения рассматриваемого опасного фактора;

- неопределенность в оценке величин ущерба и вероятности.

В основе такой характеристики риска лежит статистический подход, который рассматривает риск как возможность (вероятность, неопределенность) наступления неблагоприятного события и количественной меры такого события (ущерба).

Впервые понятия «неопределенность» и «риск», как научные категории, были описаны в 1921 году американским экономистом Ф. Найтом, который подчеркивал принципиальную из- меримость риска и толковал его как «измеримую неопределенность» [15]. При этом степень такой неопределенности или вероятность наступления какого-то неблагоприятного события могут быть количественно установлены [9].

Понятие «риск» логически соотносится с понятиями «опасность» и «уязвимость». Под опасностью подразумевают процесс, свойство или состояние природы, общества или техники, представляющие угрозу для жизни или благосостояния людей, объектов хозяйства или окружающей среды $[4,7,25]$.

Нормативы безопасности во всем мире еще недавно строились на концепции абсолютной безопасности, в основе которой лежит создание инженерных систем, обеспечивающих высокий уровень безопасности. Считалось, что такой подход позволит исключить любую опасность для населения и окружающей среды.

Согласно Ф3 № 7 (гл. 1, ст. 1) «Об охране окружающей среды» от 10.01.2002 г. (ред. от 29.07.2018 г.) под экологическим риском понимают вероятность наступления события, имеющего неблагоприятные последствия для природной среды и вызванного негативным воздействием хозяйственной и иной деятельности, чрезвычайными ситуациями природного и техногенного характера [20].

Экологический риск, как один из видов риска, можно классифицировать, опираясь на базовую классификацию рисков, по масштабу проявления, по степени допустимости, по прогнозированию, по возможности предотвращения, по возможности страхования (табл. 1).

Классификация экологических рисков [14]

Таблица 1

\begin{tabular}{|c|c|c|}
\hline $\begin{array}{l}\text { № } \\
\text { п/п }\end{array}$ & Наименование риска & Характеристика \\
\hline 1 & природно-экологические риски & $\begin{array}{c}\text { риски, обусловленные изменениями в окружающей } \\
\text { природной среды }\end{array}$ \\
\hline 2 & технико-экологические риски & риски, обусловленные появлением и развитием техносферы \\
\hline 3 & $\begin{array}{c}\text { риск устойчивых техногенных } \\
\text { воздействий }\end{array}$ & $\begin{array}{c}\text { риск, связанный с изменениями окружающей среды в } \\
\text { результате обычной хозяйственной деятельности }\end{array}$ \\
\hline 4 & $\begin{array}{c}\text { риск катастрофических } \\
\text { воздействий }\end{array}$ & $\begin{array}{c}\text { риск, связанный с изменениями окружающей среды в } \\
\text { результате техногенных катастроф, аварий, инцидентов }\end{array}$ \\
\hline 5 & социально-экологические риски & $\begin{array}{c}\text { риски, обусловленные защитной реакцией государства и } \\
\text { общества на обострение экологической обстановки }\end{array}$ \\
\hline 6 & эколого-нормативный риск & $\begin{array}{c}\text { риск, обусловленный принятием экологических законов и } \\
\text { норм или их постоянным ужесточением }\end{array}$ \\
\hline 7 & эколого-политический риск & риск, обусловленный экологическими акциями протеста \\
\hline 8 & экономо-экологические риски & $\begin{array}{c}\text { риски, обусловленные финансово-хозяйственной } \\
\text { деятельностью }\end{array}$ \\
\hline
\end{tabular}


На основе классификации экологических рисков можно выделить субъекты, чья деятельность является источником повышенной опасности для окружающей среды, и предпринять мероприятия по предотвращению реализации рисков, по защите объекта от воздействия на него экологических факторов риска $[12,26,27,30,31,32]$.

А.Г. Шмаль в своей работе «Факторы экологической опасности и экологические риски» (2010) представил экологические риски в виде четырех последовательных [24]:

I блок: идентификация экологического риска, потенциально проявляющегося на оцениваемом объекте, которая представляет собой комплекс объективных и субъективных методов использования информации.

II блок: оценка рисков, которая позволяет выявить степень опасности воздействия на окружающую среду и здоровья человека в определенной ситуации.

III блок: мониторинг экологических рисков, направленный на нормирование воздействий на окружающую среду и контроль этого воздействия.

IV блок: управление экологическим риском, направленное на разработку стратегий по уменьшению негативных воздействий на окружающую среду в процессе хозяйственной деятельности предприятий.

Экологические риски отличаются от случайных тем, что их можно предотвратить, гра- мотно построив риск-анализ хозяйственной деятельности предприятия.

Уровень экологического риска определяет уровень экологической безопасности, то есть обеспечения защиты жизненно важных интересов личности, общества, государства и окружающей среды от негативных воздействий антропогенного и природного характера. Экологическая безопасность достигается снижением экологического риска до некоторого приемлемого уровня [6].

Одной их составляющей экологического риска является оценка воздействия загрязняющих веществ на человека и окружающую природную среду. Такой риск в 70-80 \% случаев формируется от хозяйственной деятельности предприятий-природопользователей. Анализ эффективности способов минимизации экологических рисков предприятий необходим для оптимизации управленческих решений.

Основные методы по управлению экологическими рисками были предложены Мочаловой Л.А. (2009), которые могут применяться в зависимости от сложившейся ситуации к любому рискообразующему фактору и оценке потенциально возможного экологического ущерба (табл. 2).

Предложенные автором методы носят последовательный характер, при этом предприятие может разрабатывать и корректировать свою стратегию в зависимости от отраслевой специфики производства.

Таблица 2

\section{Возможные методы управления экологическими рисками}

(Составлено автором по [5, 13])

\begin{tabular}{|c|c|c|c|}
\hline $\begin{array}{c}\text { Метод } \\
\text { управления }\end{array}$ & $\begin{array}{c}\text { Рискообразующие } \\
\text { факторы }\end{array}$ & $\begin{array}{c}\text { Потенцильно } \\
\text { возможный } \\
\text { экологический ущерб }\end{array}$ & $\begin{array}{c}\text { Стратегия действия } \\
\text { предприятия }\end{array}$ \\
\hline $\begin{array}{c}\text { сохранение } \\
\text { (принятие) } \\
\text { экологического } \\
\text { риска }\end{array}$ & $\begin{array}{c}\text { макро- и } \\
\text { микроуровень } \\
\text { внешних факторов }\end{array}$ & низкий & $\begin{array}{c}\text { предприятие не предпринимает } \\
\text { никаких действий по отношению к } \\
\text { возникшему риску }\end{array}$ \\
\hline $\begin{array}{c}\text { передача } \\
\text { экологического } \\
\text { риска партнерам }\end{array}$ & $\begin{array}{c}\text { микроуровень } \\
\text { внених факторов }\end{array}$ & средний & $\begin{array}{c}\text { риск в полном или частичном } \\
\text { объеме переносится на другие } \\
\text { предприятия, в качестве которых } \\
\text { могут выступать поставщики, } \\
\text { покупатели и другие региональные } \\
\text { предприятия }\end{array}$ \\
\hline $\begin{array}{c}\text { передача } \\
\text { экологического } \\
\text { риска финансовым } \\
\text { институтам }\end{array}$ & $\begin{array}{c}\text { внешнренние и } \\
\text { внкторы }\end{array}$ & высокий & $\begin{array}{c}\text { риск передается страховым, } \\
\text { банковским и другим финансово- } \\
\text { кредитным организациям }\end{array}$ \\
\hline
\end{tabular}


Окончание таблицы 2

\begin{tabular}{|c|c|c|c|}
\hline $\begin{array}{c}\text { Метод } \\
\text { управления }\end{array}$ & $\begin{array}{c}\text { Рискообразующие } \\
\text { факторы }\end{array}$ & $\begin{array}{c}\text { Потенциально } \\
\text { возможный } \\
\text { экологический ущерб }\end{array}$ & $\begin{array}{c}\text { Стратегия действия } \\
\text { предприятия }\end{array}$ \\
\hline самострахование & $\begin{array}{c}\text { внутренние и } \\
\text { внешние факторы }\end{array}$ & низкий & $\begin{array}{c}\text { предприятие создает специальные } \\
\text { резервные фонды, которые при } \\
\text { наступлении непредвиденной } \\
\text { экологической ситуации будут } \\
\text { являться источником } \\
\text { компенсационных выплат }\end{array}$ \\
\hline $\begin{array}{c}\text { распределение } \\
\text { экологического } \\
\text { риска }\end{array}$ & $\begin{array}{c}\text { микроуровень } \\
\text { внешних факторов, } \\
\text { реже - макро- и } \\
\text { мезоуровень } \\
\text { внешних факторов }\end{array}$ & высокий & $\begin{array}{c}\text { предприятие распределяет } \\
\text { собственный экологический риск } \\
\text { между различными сторонами, в } \\
\text { качестве которых могут выступать } \\
\text { партнеры по бизнесу, финансовые } \\
\text { институты, государство } \\
\end{array}$ \\
\hline $\begin{array}{c}\text { сокращение } \\
\text { вероятности } \\
\text { экологического } \\
\text { события } \\
\end{array}$ & $\begin{array}{c}\text { внутренние } \\
\text { факторы, макро- и } \\
\text { мезоуровень } \\
\text { внешних факторов } \\
\end{array}$ & средний & $\begin{array}{c}\text { предприятие разрабатывает } \\
\text { стратегию, основанную на анализе } \\
\text { в области прогнозирования } \\
\text { экологической ситуации } \\
\end{array}$ \\
\hline $\begin{array}{c}\text { управление и } \\
\text { локализация риска }\end{array}$ & $\begin{array}{c}\text { внутренние } \\
\text { факторы }\end{array}$ & средний & $\begin{array}{c}\text { возможно лишь в случае } \\
\text { определения источника риска }\end{array}$ \\
\hline $\begin{array}{c}\text { избежание } \\
\text { экологического } \\
\text { риска } \\
\end{array}$ & $\begin{array}{c}\text { внутренние и } \\
\text { внешние факторы }\end{array}$ & высокий & $\begin{array}{c}\text { уменьшение вероятности } \\
\text { наступления риска и уменьшения } \\
\text { объемов возможных потерь }\end{array}$ \\
\hline
\end{tabular}

В деятельности промышленного предприятия для корректного определения уровня риска, необходимо различать «начальный» и «финальный» риск, поэтому при принятии управленческих решений необходимо учитывать вероятность уменьшения величины «начального» риска до уровня «финального».

Управление рисками должно строиться также с учетом определенных принципов: комплексности; своевременности; непрерывности; законности; обоснованности; экономической целесообразности и сопоставимости возможного ущерба и затрат на обеспечение экологической безопасности предприятия; специализации; взаимодействия и координации; совершенствования и централизации управления $[4,10,17,23]$. Каждый из принципов является важным при принятии управленческих решений в отношении возникновения рисковой ситуации на предприятии. В управлении риском должен быть учтен также принцип региональности, который включает в себя весь спектр совокупных региональных экологических угроз.

Сам процесс принятия решений обычно состоит из нескольких этапов: производится сбор информации и ее обработка с выявлени- ем вероятных рисков, способных оказать наибольшее влияние на процесс. На основе полученных результатов происходит подготовка вариантов управленческого решения. Каждый из вариантов прорабатывается на предмет возможных последствий от принятия неверных решений, далее дается сводная количественная оценка экологических рисков. На основе полученных результатов проведенного анализа принимается окончательное решение.

Согласно данным официальной статистики, на территории Волгоградской области организации по видам экономической деятельности распределены следующим образом: сельское, лесное хозяйство, охота, рыболовство и рыбоводство - 1712, добыча полезных ископаемых - 103, обрабатывающие производства 3119 (по данным на 01.01.2018) [19]. Это те организации, хозяйственная деятельность которых представляет наибольший интерес для реального сектора экономики региона.

Анализируя хозяйственную деятельность некоторых градообразующих предприятий города и области, можно прийти к выводу, что необходимо систематизировать управление рисками как многоступенчатый процесс. Целью данного процесса является уменьшение или ком- 
A.А.Матвеева. Управление рисками для обеспечения экологической безопасности на предприятиях

пенсация убытков хозяйствующих субъектов при наступлении неблагоприятных событий $[21,22]$.

Экологический риск как категория «чистого» риска имеет свою специфику по характеру и способам устранения в зависимости от вида экономической деятельности хозяйствующих субъектов.

Обобщенный алгоритм управления экологическим риском на предприятиях представлен на рисунке 1 , при этом расчет наносимого эколого-экономического ущерба компонентам окружающей среды проходит параллельно с оценкой риска, а также при принятии и разработке соответствующей стратегии действия должны учитываться риски, связанные с компенсацией этого ущерба.

Классическими инструментами покрытия экологических рисков являются такие инструменты как планирование производства эколо- гически чистой продукции, страхование ответственности за экологическое загрязнение и самострахование. Рынок экологического страхования на региональных производствах практически не развит, поэтому ключевым инструментом будет являться процесс внедрения наилучших доступных технологий в производство.

Выбор оптимальных методов управления рисками и создание отлаженной системы на предприятии позволит обеспечить не только экологическую, но и финансовую безопасность [11].

Однако не следует забывать, что риск это переменная величина, которая изменяется с учетом внешних факторов окружающей среды, тем самым меняются характеристики риска. Процесс управления экологическим риском должен учитывать эти особенности и меняться в зависимости от деятельности каждого конкретного предприятия.

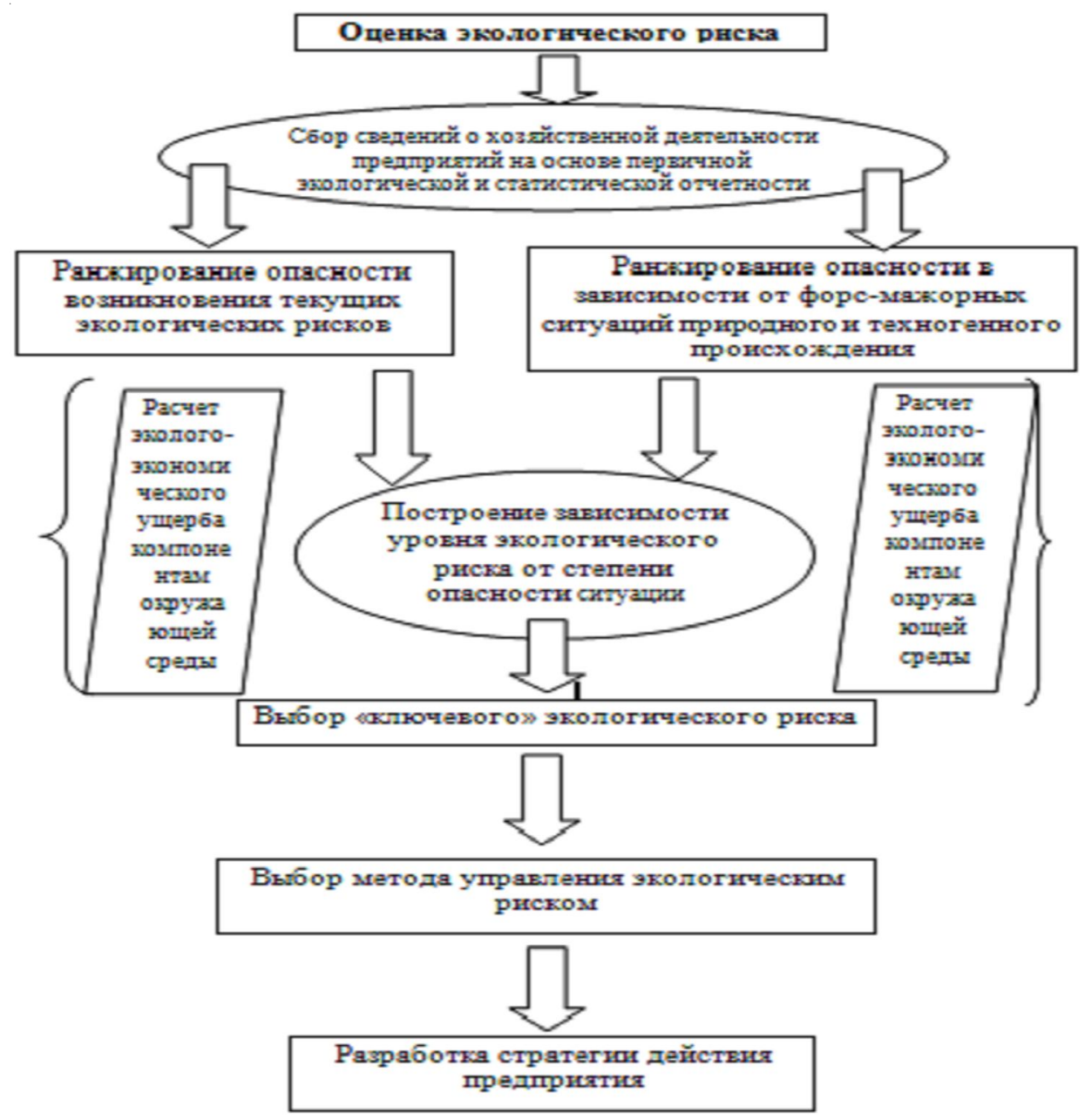

Рис. 1. Обобщенный алгоритм управления экологическими рисками на предприятиях

Примечание. Составлено автором по: [2, 3, 8, 16, 18]. 


\section{СПИСОК ЛИТЕРАТУРЫ}

1. Акимов, В.А. Основы анализа и управления риском в природной и техногенной сферах / В.А. Акимов, В.В. Лесных, Н.Н. Радаев. - М.: Деловой экспресс, 2004. - 352 с.

2. Боков, В.А. Оценка экологических опасностей / В.А. Боков и др. - Симферополь: ДОЛЯ, 2012. $248 \mathrm{c}$.

3. Бородин, А.И. Концептуальная модель управления экологическими рисками / А.И. Бородин, Е.В. Бильчак // Вектор науки ТГУ. Серия: Экономика и управление. - 2012. - №4(11). - С. 20-22.

4. Гиляровская, Л.Т. Анализ и оценка финансовой устойчивости коммерческого предприятия / Л.Т. Гиляровская, А.А. Вехорева. - СПб.: Питер, 2003. -256 с.: ил.

5. Гинко, В.И. Экологический риск в системе управления риском / В.И. Гинко // В мире научных открытий. - 2013. - №7.2(43). - С. 301-312.

6. Данилов-Данильян, В.И. Экологическая безопасность. Общие принципы и российский аспект / В.И. Данилов-Данильян и др. - М.: Изд-во МНЭПУ, 2001.-332 c.

7. Елин, А.М. Риск как неотьемлемый элемент управления производственной деятельностью / А.М. Елин, А.В. Тимашов // Вестник ПНИПУ. Безопасность и управление рисками. - 2016. - № 5. C. 220-229.

8. Живора, А.А. Анализ рисковых ситуаций на предприятиях / А.А. Живора // Организатор производства. -2015 . - №2. - С. 50-57.

9. Иванцова, Е.А. Управление эколого-экономической безопасностью промышленных предприятий/Е.А. Иванцова, В.А. Кузьмин//Вестник Волгоградского государственного университета Серия 3. Экономика. Экология.-2014. - №5 (28). - С. 136-146.

10. Измалков, В.И. Техногенная и экологическая безопасность и управление риском / В.И. Измалков, А.В. Измалков. - СПб.: НИЦЭБ РАН, 1998. - 482 с.

11. Князевская, Н.В. Принятие рискованных решений в экономике и бизнесе / Н.В. Князевская, В.С. Князевский. - М.: «Контур», 1998. - 160 с.

12. Матвеева, А.А. Системный подход в обеспечении экологической безопасности на региональных предприятиях / А.А. Матвеева // Рациональное природопользование: традиции и инновации. Материалы II Международной конференции, Москва, МГУ, 17-18 ноября 2017 г. / Под общ. ред. проф. М.В. Слипенчука. - М.: Изд-во КДУ, 2017. - С. 246-249.

13. Мочалова, Л.А. Методология и механизмы обеспечения экологической устойчивости промышленного предприятия: автореф. дис. на соиск. учен. степени доктора эконом. наук (08.00.05) / Мочалова Людмила Анатольевна; ГОУ ВПО «Уральский государственный горный университет», 2009. - 39 с.
14. Мурзалевский, А.А. Экологические риски: теория и практика / А.А. Мурзалевский, Л.Н. Карлин. -СПб.: РГГМУ: ВВМ, 2011.-448 с.

15. Найт, Ф.Х. Риск, неопределенность и прибыль / Ф.Х. Найт. - М.: Дело, 2003. - 360 с.

16. Темпан, Л.Н. Риски в экономике / Л.Н. Темпан. - М.: ЮНИТИ-ДАНА, 2002. - 380 с.

17. Титов, В.И. Экономика предприятия / В.И. Титов. - М.: Изд-во «Дашков и К0», 2004. - 462 с.

18. Попов, Е.В. Эмпирическая оценка экологического менеджмента предприятий / Е.В. Попов / / Менеджмент в России и за рубежом. - 2014. № 1.- С. 129-135.

19. Распределение организаций по видам экономической деятельности (по данным государственной регистрации). Официальный сайт Волгоградстата. - Режим доступа: http://www.volgastat.gks.ru/wps/ $\mathrm{wcm} / \mathrm{connect/rosstat/ts/volgastat/resources/}$ 45bcd280442e54bdac89affa17e1e317.

20. Ф3 № 7 «Об охране окружающей среды» от 10.01.2002 (ред. от 29.07.2018). Информационная система: КонсультантПлюс. - Режим доступа: http:// www.consultant.ru/document/cons_doc_LAW_34823/.

21. Хабарова, Е.И. Оценка и управление риском как метод обеспечения экологической безопасности / Е.И. Хабарова, С.В. Никитина // Вестник МИТХТ. Серия: социально-гуманитарные науки и экология. - 2015. -№4. - С. 102-108.

22. Хаустов, А.П. Экологическое проектирование и риск-анализ / А.П. Хаустов, М.М. Редина, П.Ю. Силаева. - М.: РУДН, 2008. - 320 с.

23. Чернова, Г.В. Управление рисками / Г.В. Чернова, А.А. Кудрявцева. - М.: Изд-во Проспект, 2005. - $160 \mathrm{c}$.

24. Шмаль, А.Г. Факторы экологической опасности и экологические риски / А.Г. Шмаль. - Бронницы: МП «ИКЦ БНТВ», 2010. - 181 с.

25. Brown, A.E.P. 1999, «Risk analysis: An investment in engineering», Process Safety Progress, vol. 18, no. 2, pp. 121-125.

26. Egorova, O. 2011, Environmental safety management in the context of innovative development of enterprises, Annals of DAAAM and Proceedings of the International DAAAM Symposium, pp. 1169. Conf. Ser. 106302.

27. Selim, A.M., Yousef, P.H.A. \& Hagag, M.R. 2019, «Risk allocation for infrastructure projects by PPPs - Under environmental management and risk assessment mechanisms», International Journal of Risk Assessment and Management, vol. 22, no. 1, pp. 89108. DOI: 10.1504/IJRAM.2018.096698.

28. Kiseleva, T.V. \& Mikhailov, V.G. 2018, «Management of current environmental costs contributing to reduce eco-economic risks», IOP Conference Series: Earth and Environmental Science. DOI: 10.1088/1755-1315/206/1/012050. 
29. Khvesyk, M., Obykhod, H., Bystryakov, I. \& Khvesyk, Y. 2018, «Assessment of the safety of environment in terms of sustainable development», Economic Annals-XXI, vol. 170, no. 3-4, pp. 22-26. DOI: 10.21003/ea.V170-04.

30. Krokhina, J.A., Vinogradova, T., Grishnova, E.Y., Zhdanov, S.P., Borisova, O.V., Ostanin, L.M., Popova, O.V. \& Kutlin, N.G. 2018, «Environmental risk management system projecting of industrial enterprises», Ekoloji, vol. 27, no. 106, pp. 735-744. ISSN: 13001361.

31. Majid Ezzati1, Jurg Utzinger2, Sandy Cairncross3, Aaron J Cohen4, Burton H Singer Environmental risks in the developing world: exposure indicators for evaluating interventions, programmes, and policies Protected by http://jech.bmj.com/J Epidemiol Community Health: first published as 10.1136/ jech.2003.019471 on 14 December 2004., pp. 15-22.

32. Chapter Eight «Environmental Risk Assessment» / Environmental Management Science and Engineering for Industry, 2017, pp. 135-152. https://doi.org/10.1016/B978-0-12-811989-1.00008-7.

\section{REFERENCES}

1. Akimov V.A., Lesnyh V.V., Radaev N.N. Osnovy analiza i upravlenija riskom v prirodnoj i tehnogennoj sferah [Fundamentals of risk analysis and management in natural and man-made areas]. Moscow, Business Express, 2004. 352 p.

2. Bokov V.A. i dr. Ocenka jekologicheskih opasnostej [Environmental Hazards Assessment]. Simferopol: SHARE, 2012. 248 p.

3. Borodin A.I. Konceptual'naja model' upravlenija jekologicheskimi riskami [Conceptual model of environmental risk management]. Vektor nauki TGU. Serija: Jekonomika i upravlenie - TSU science vector. Series: Economics and Management, 2012, no. 4(11), pp. 20-22.

4. Giljarovskaja L.T., Vehoreva A.A. Analiz i ocenka finansovoj ustojchivosti kommercheskogo predprijatija [Analysis and evaluation of financial stability of a commercial enterprise]. Sankt-Petersburg, Peter, 2003. 256 p. ill.

5. Ginko V.I. Jekologicheskij risk v sisteme upravlenija riskom [Environmental risk in the risk management system]. V mire nauchnyh otkrytij - In the world of scientific discoveries, 2013, no. 7.2 (43), pp. 301-312.

6. Danilov-Danil'jan V.I. i dr. Jekologicheskaja bezopasnost'. Obshhie principy i rossijskij aspekt [Environmental Safety. General principles and the Russian aspect]. Moscow, Publishing house MNEPU, 2001. 332 p.

7. Elin A.M., Timashov A.V. Risk kak neot\#emlemyj jelement upravlenija proizvodstvennoj dejatel'nost'ju [Risk as an integral element of production management]. Vestnik PNIPU. Bezopasnost' i upravlenie riskami - Bulletin PSTU. Security and risk management, 2016, no. 5, pp. 220-229.

8. Zhivora A.A. Analiz riskovyh situacij na predprijatijah [Analysis of risk situations in enterprises] Organizator proizvodstva - Production Organizer, 2015, no. 2, pp. 50-57.

9. Ivantsova E.A., Kuzmin. Upravlenie ecologoeconomicheskoi bezopasnostyu promyshlennyx predpriyatii [Management of ecological and economic security of industrial enterprises] // Vestnik Volgogradskogo gosudarstvennogo universiteta. Seria 3: Economika. Ecologia [Vestnik Volgogradskogo gosudarstvennogo Federal. Seria 3: Economika. Ecologia], 2014, no 5, pp. 136-146.

10. Izmalkov, V.I., Izmalkov, A.V. Tehnogennaja i jekologicheskaja bezopasnost' i upravlenie riskom [Technogenic and environmental safety and risk management]. Sankt-Petersburg, NICEB RAS, 1998. 482 p.

11. Knjazevskaja, N.V., Knjazevskij, V.S. Prinjatie riskovannyh reshenij v jekonomike i biznese [Making risky decisions in economics and business]. Moscow, Kontur, 1998. 160 p.

12. Matveeva, A.A. Sistemnyj podhod v obespechenii jekologicheskoj bezopasnosti na regional'nyh predprijatijah [A systematic approach to ensuring environmental safety in regional enterprises]. Racional'noe prirodopol'zovanie: tradicii i innovacii. Materialy II Mezhdunarodnoj konferencii, Moskva, MGU, 17-18 nojabrja 2017 g. / Pod obshh. red. prof. M.V. Slipenchuka [Environmental management: traditions and innovations. Proceedings of the II International Conference, Moscow, MSU, November 17-18, 2017 / Ed. ed. prof. Mv Slipenchuk]. Moscow, Publishing house KDU, 2017, pp. 246-249.

13. Mochalova, L.A. Metodologija i mehanizmy obespechenija jekologicheskoj ustojchivosti promyshlennogo predprijatija. Avtoref. Diss. na soisk. uchen. stepeni doktora jekonom. nauk [Methodology and mechanisms to ensure the environmental sustainability of industrial enterprises. Author. dis. on the competition scholarly Degree of Doctor of Economics Sciences]. Ural, 2009. 39 p.

14. Murzalevskij, A.A., Karlin, L.N. Jekologicheskie riski: teorija i praktika [Environmental risks: theory and practice]. Sankt-Petersburg, RSHU: BBM, 2011. 448 p.

15. Najt, F.H. Risk, neopredelennost' i pribyl' [Risk, uncertainty and profit]. Moscow, Delo, 2003. $360 \mathrm{p}$.

16. Tempan, L.N. Riski v jekonomike [Risks in the economy]. Moscow, NITY-DANA, 2002.380 p.

17. Titov, V.I. Jekonomika predprijatija [Enterprise Economics]. Moscow, Publishing house "Dashkov and K0", 2004. 462 p. 


\section{ЭКОЛОГИЯ И ПРИРОДОПОЛЬЗОВАНИЕ}

18. Popov, E.V. Jempiricheskaja ocenka jekologicheskogo menedzhmenta predprijatij [Empirical assessment of environmental management of enterprises]. Menedzhment v Rossii i za rubezhom Management in Russia and abroad, 2014, no.1, pp. 129135.

19. Raspredelenie organizacij po vidam jekonomicheskoj dejatel'nosti (po dannym gosudarstvennoj registracii). Oficial'nyj sajt Volgogradstata [Distribution of organizations by type of economic activity (according to state registration]. Official site of Volgogradstat) Available at: http:// www.volgastat.gks.ru/wps/wcm/connect/rosstat_ts/ $\mathrm{v}$ o l g a s t a t / r e s o u r c e s / 45bcd280442e54bdac89affa17e1e317 (accessed 9 January 2019).

20. FZ № 7 «Ob ohrane okruzhajushhej sredy» ot 10.01.2002 (red. ot 29.07.2018). Informacionnaja sistema: Konsul'tantPljus (Federal Law No. 7 «On Environmental Protection» dated January 10, 2002 (as amended on 07/29/2018). Information system: Consultant Plus) Available at: http:// w w w . c o n s u l t a n t. r u/d o c u me n t/ cons_doc_LAW_34823/(accessed 8 January 2019).

21. Habarova, E.I., Nikitina, S.V. Ocenka i upravlenie riskom kak metod obespechenija jekologicheskoj bezopasnosti [Risk assessment and management as a method of ensuring environmental safety]. Vestnik MITHT. Serija: social'no-gumanitarnye nauki i jekologija - Bulletin MITHT. Series: social sciences and ecology, 2015, no. 4, pp. 102-108.

22. Haustov, A.P., Redina, M.M., Silaeva, P.Ju. Jekologicheskoe proektirovanie i risk-analiz [Environmental design and risk analysis]. Moscow, RUDN, 2008.320 p.

23. Chernova, G.V., Kudrjavceva, A.A. Upravlenie riskami [Risk management]. Moscow, Publishing House Prospectus, 2005. $160 \mathrm{p}$.

24. Shmal', A.G. Faktory jekologicheskoj opasnosti i jekologicheskie riski [Environmental hazards and environmental risks]. Bronnitsy, 2010. 181 p.
25. Brown, A.E.P. 1999, «Risk analysis: An investment in engineering», Process Safety Progress, vol. 18, no. 2, pp. 121-125.

26. Egorova, O. 2011, Environmental safety management in the context of innovative development of enterprises, Annals of DAAAM and Proceedings of the International DAAAM Symposium, pp. 1169. Conf. Ser. 106302.

27. Selim, A.M., Yousef, P.H.A. \& Hagag, M.R. 2019, «Risk allocation for infrastructure projects by PPPs - Under environmental management and risk assessment mechanisms», International Journal of Risk Assessment and Management, vol. 22, no. 1, pp. 89108. DOI: 10.1504/IJRAM.2018.096698.

28. Kiseleva, T.V. \& Mikhailov, V.G. 2018, «Management of current environmental costs contributing to reduce eco-economic risks», IOP Conference Series: Earth and Environmental Science. DOI: 10.1088/1755-1315/206/1/012050.

29. Khvesyk, M., Obykhod, H., Bystryakov, I. \& Khvesyk, Y. 2018, "Assessment of the safety of environment in terms of sustainable development», Economic Annals-XXI, vol. 170, no. 3-4, pp. 22-26. DOI: 10.21003/ea.V170-04.

30. Krokhina, J.A., Vinogradova, T., Grishnova, E.Y., Zhdanov, S.P., Borisova, O.V., Ostanin, L.M., Popova, O.V. \& Kutlin, N.G. 2018, «Environmental risk management system projecting of industrial enterprises», Ekoloji, vol. 27, no. 106, pp. 735-744. ISSN: 13001361.

31. Majid Ezzati1, Jurg Utzinger2, Sandy Cairncross3, Aaron J Cohen4, Burton H Singer Environmental risks in the developing world: exposure indicators for evaluating interventions, programmes, and policies Protected by http://jech.bmj.com/J Epidemiol Community Health: first published as 10.1136/ jech.2003.019471 on 14 December 2004., pp. 15-22.

32. Chapter Eight «Environmental Risk Assessment» / Environmental Management Science and Engineering for Industry, 2017, pp. 135-152. https://doi.org/10.1016/B978-0-12-811989-1.00008-7.

\section{Information about the Author}

Anna A. Matveeva, Candidate of sciences (Agriculture), Associate professor, Department of Ecology and Nature Management, Volgograd State University, Prosp. Universitetsky, 100, 400062 Volgograd, Russian Federation, matveeva@volsu.ru.

\section{Информация об авторе}

Анна Александровна Матвеева, кандидат сельскохозяйственных наук, доцент кафедры экологии и природопользования, Волгоградский государственный университет, просп. Университетский, 100, 400062 г. Волгоград, Российская Федерация, matveeva@volsu.ru. 